These QTL regions will be used to produce extreme animals (homozygous for resistant QTL alleles or susceptible QTL alleles). Animals will be challenged and various tissue/cell samples collected in order to identify affected function by gene expression profiling. By this way, genes and potentially their causal mutations may be identified.

The aim of this work was to provide genes (causal mutation or associated markers) to select for nematode resistance in the already implemented sheep breeding schemes. In addition, this gene selection could be an alternative or a further way of control in farms where parasites have become resistant to classical chemical treatments.

Moreover, because of the high efficiency of gene selection, some caution is necessary before using gene mutation. The most important one is to estimate the effect of the mutation(s) on the other traits of interest in order to avoid an unfavourable correlated response. For example, studies considering genes such as Major Histocompatibility Complex genes in the chicken, showed that the selection of resistant alleles for a disease is able to select susceptibility to other diseases. Finally, concerning disease resistance, because of the possible adaptation of the pathogen to the resistant host, the selection on several genes simultaneously or firstly on gene, and after on phenotype within "resistant" animals, is a less risky strategy than selection on a unique gene. The breakdown of resistance was previously observed during the selection of apple trees to Venturia inaequalis (Parisi et al., 2004).

To conclude, a well-thought-out gene selection for resistance to parasites in sheep is an easy and efficient strategy to control parasites, especially in tropical countries where several agents have developed resistances to anthelmintics.

\title{
References
}

Moreno C, Gruner L, Scala A, Mura L, Schibler L, Amigues Y, Sechi T, Jacquiet P, Francois D and Sechi S 2006. QTL for resistance to internal parasites in two designs based on natural and experimental conditions of infection. Proceedings of the 8th World Congress on Genetics Applied to Livestock Production.

Parisi L, Fouillet V, Schouten HJ, Groenwold R, Laurens FND, Didelot F, Evans K, Fischer C, Gennari F and Kemp H 2004. Variability of the pathogenicity of Venturia inaequalis in Europe.

\section{Contributions of the Creole goat model to the understanding of the genetic resistance to gastrointestinal nematode infections}

\author{
Claudia de la Chevrotière ${ }^{\dagger}$
}

INRA, UR143, Unité de Recherches Zootechniques, 97170 Petit Bourg, Guadeloupe, France

\section{Introduction}

Infections by gastrointestinal nematode (GIN) parasites are one of the major constraints to small ruminant production in tropical climates. The presence of resistant animals opened the door to the investigation of the genetic component of the nematode resistance. The Creole goat population is facing continual parasite challenges and there are differences between individuals for resistance despite a good adaptation to this environment. Therefore, the Creole goat is an interesting model for the study of all components of nematode resistance. This summary will focus on different studies on (i) the genetic variability (ii) the genomic regions associated with resistance and on (iii) the immune mechanisms behind resistance.

\section{Experimental flock}

The experimental flock of INRA has been reared since the 1980s and phenotyped for GIN resistance since 1995. All animals are raised on pasture all year long and naturally exposed to a mixed nematode infection.

\section{Genetic variability}

The assessment of the genetic variability of resistance against GIN was intended to evaluate the possibility to include nematode resistance into a breeding scheme. The data collected for several phenotypic traits such as FEC (faecal egg counts), PCV (packed-cell volume), circulating eosinophil counts and bodyweight have been used to estimate the intrabreed genetic variability for resistance to GIN. The analysis of the variability through the post-weaning period showed a positive evolution of the heritability with the age of the animal for FEC and PCV (de la Chevrotière et al., 2010). The maximum genetic variability was found at 11 months of age with estimates of heritability of 0.2 in average for all traits (Mandonnet et al., 2001). Correlations between different traits showed that the PCV is more a resilience trait as indicated by the positive correlation with bodyweight. The eosinophil counts are negatively correlated with FEC and reflect their participation in the

\footnotetext{
${ }^{\dagger}$ E-mail: Nathalie.Mandonnet@antilles.inra.fr
} 
immune mechanisms of resistance. A negative correlation with bodyweight makes it unsuitable in a breeding scheme. The FEC estimated at 11 months of age is thus best suited to be included in a breeding scheme as there is no conflict with any performance trait and the absence of maternal genetic effects makes its selection favourable. This criterion reflects several mechanisms of resistance, making difficult the adaptation of the parasites against the increasing resistance of the host. In addition, this selection could also be optimized using genetic markers of resistance.

\title{
Genes of resistance
}

The study performed on Creole goats for quantitative trait loci (QTL) associated with GIN is the only one available in this species (de la Chevrotière et al., 2009). A total of 13 genomic regions associated with GIN resistance were detected. Five QTL were significant at the $1 \%$ chromosome-wide threshold and the average effect of most QTL exceeds one phenotypic standard deviation. Many QTL were found on chromosomes known to carry candidate genes such as the interferon gamma or the IgE gene. The use of SNP chip will complement these first results and provide a more powerful detection of QTL.

\section{Immune mechanisms}

Finding QTL near immunity genes support the hypothesis that the genetic resistance is partly mediated by immunological processes such as proliferation of mucosal mast cells, eosinophils and production of immunoglobulins. Circulating eosinophil counts significantly increased after experimental infection with $\mathrm{H}$. contortus in Creole kids along with levels of IgA and IgE (Bambou et al., 2008). Another study showed a higher level of LTCD4+ in susceptible animals and a higher level of circulating lymphocytes B in resistant animals at 35 days post infection (Bambou et al., 2009). These initial results confirm the implication of immune mechanisms in the development of resistance to GIN in Creole goats. IgA and $\mathrm{lg} \mathrm{E}$ are also under a genetic control as indicated by medium estimates of heritability (unpublished results).

\section{Conclusion}

The Creole goat provides interesting results on the genetic resistance of nematode and its mechanisms. It is also a good model for comparison with sheep results. Moreover, the different results obtained are leading directly to practical applications.

\section{Acknowledgements}

The authors thank the European Community (FEOGA), "La Région Guadeloupe" and EADGENE Network of Excellence for their financial support.

\section{References}

Bambou JC, de la Chevrotière C, Varo H, Arquet R, Kooyman FNJ and Mandonnet N 2008. Veterinary Parasitology 158, 311-318.

Bambou JC, Gonzalez-Garcia E, de la Chevrotière C, Arquet R, Vachiéry N and Mandonnet N 2009. Small Ruminant Research 82, 34-39.

de la Chevrotière C, Bishop S, Moreno C, Arquet R, Bambou JC, Schibler L, Amigues Y and Mandonnet N 2009. In Proceedings of $60^{\text {th }}$ Annual Meeting of the European Association for Animal Production.

de la Chevrotière C, Gunia M, Menendez-Buxadera A, Bambou JC and Mandonnet N 2010. In Proceedings of $9^{\text {th }}$ World Congress on Genetics Applied to Livestock Production. Mandonnet N, Aumont G, Fleury J, Arquet R, Varo H, Gruner L, Bouix J and Vu Tien Khang J 2001. Journal of Animal Science 79, $1706-1712$.

\section{doi:10.1017/S2040470010000154}

\section{Production traits of St. Croix White and Dorper $\times$ St. Croix White ewes in an accelerated lambing system in the tropics}

\author{
Robert W. Godfrey ${ }^{\dagger}$, Raina E. Dodson and Rosemary C. Ketring \\ University of the Virgin Islands, Agricultural Experiment Station, St. Croix, USVI
}

Over the past several years there has been an increased interest in using Dorper sheep in crossbreeding programs with local sheep breeds in the Caribbean. The Dorper breed was chosen for its heavy muscling in an attempt to increase the growth rate and size of lambs produced for the local market. It has been shown that Dorper $\times$ St. Croix White lambs grow faster and yield heavier carcasses than St. Croix White lambs when they are raised on either a concentrate or forage ration after weaning (Dodson et al., 2005; Godfrey and Weis, 2005). The Dorper was developed for an arid environment and is not known for prolificacy, unlike the indigenous hair sheep in the Caribbean that have been selected for a humid environment and are prolific. There is little information on how Dorper $\times$ St. Croix White crossbred ewes will perform under tropical conditions found in the Caribbean. The objective of this study was to compare production traits of St. Croix White and

\footnotetext{
† E-mail: rgodfre@uvi.edu
} 